\title{
Send us your briefs! - a new CMAJ call for medical images
}

\author{
Eric Wooltorton, Claire Kendall
}

$\mathrm{N}$ early 5 years ago, CMAJ launched Clinical Vistas, a case-based imaging column, ${ }^{1}$ in order to increase the clinical and visual content of the Journal. Since that time readers have been provided glimpses of a variety of interesting and important clinical scenes. Cases have highlighted typical presentations of rare conditions ${ }^{2}$ as well as common complaints caused by unusual diseases. ${ }^{3}$ One reader recently joked that we should change the name of the column to "Infections presenting as cancer, and vice versa." Primarily educational, but with a tone deliberately less "gawky" than many imaging columns, Clinical Vistas was designed to allow readers to imagine themselves in the treating physician's decision-making shoes. In the end, the column has been primarily educational.

Readership surveys and download statistics from www .cmaj.ca have suggested that the column is well received. As editors we have, however, been disappointed that we can publish only a fraction of the cases submitted to the column. An idea was conceived for a new, briefer version of Clinical Vistas to allow multiple cases to be published in a single feature. And thus is born in this issue (see page I7IO) a new column: Clinical Vistas Briefs.

Clinical Vistas will still appear in its original form in every second issue, but it will alternate with the Briefs column. The Briefs will still cover important and rare conditions or physical signs, but will differ from the usual Clinical Vistas articles in format and length. The Briefs will be presented more as a diagnostic quiz designed to sharpen the clinician's visual recognition skills; they will also be much shorter, with few references. Armed with the bare images, accompanied only by a short clinical description (such as might be found on a radiograph or pathology requisition), readers will be asked to make a diagnostic "call." It is hoped that approaching the cases with no titles that give away the diagnosis, explanatory figure captions nor unambiguous arrow signs will make the cases more interesting. The diagnosis will be revealed on another page, with arrows as required to clarify the image, and some brief educa$\tilde{\wp}$ tional or take-home points about the condition in question.

Readers are invited to submit cases with interesting clinical images according to the criteria specified in Box I. Submissions are best sent through our online manuscript tracking system (see the link at www.cmaj.ca). It is hoped that this new column will further meet the needs of our readers and authors; we look forward to feedback from readers in the coming months.

\section{Box 1: Cases for Clinical Vistas Briefs}

Images to be published in this column:

- Photographs* of any body part, including those obtained with fundo-, gonio- or endoscopic methods and pictures of gross or micropathology

- Plain-film radiography*

- CT, MRI or any other type of scan (including tracings* such as electrocardiograms)

Submissions for Clinical Vistas Briefs must include:

- A case that is original and unpublished

- A consent form for publication, signed by the patient (a sample form is available through www.cmaj.ca)

- Clear, high-quality images ( $\geq 300$ dpi resolution) in versions without as well as with arrows, when arrows (or other labels) are helpful

- An initial caption to orient the reader (e.g., "Chest radiograph of a 20-year-old woman with hemoptysis")

- An explanation (50-200 words) of the clinical significance of the image or the case itself

- No more than 3 authors $\dagger$

- No reference citations (or 1 reference at most)

"Images such as these, which may be more likely to be seen by generalists in practice, are particularly desirable. (Scans such as CTs and MRIs will also be considered when the images are interesting or classic.)

tCoauthors must meet the usual requirements for authorship (see the Uniform Requirements, available through www.cmaj.ca).

Eric Wooltorton is an Associate Editor at CMAJ. Claire Kendall is Assistant Professor, Department of Family Medicine, University of Ottawa, Ottawa, Ont. In her former role of associate editor at $C M A J$, Dr. Kendall had a major role in conceiving this project and editing the earliest submissions to the column.

\section{REFERENCES}

I. Wooltorton E. Launching a new journal page: Clinical Vistas. CMAJ 200I;165(9): I22I-2.

2. Swartz EN. A child with kinky hair. $C M A J$ 2002;I66(II):I442-3.

3. Somani RAB, Kaban G, Cuddington $G$, et al. Appendicitis in pregnancy: a rare presentation. CMAJ 2003;I68(8):I020.

Correspondence to: Dr. Eric Wooltorton, Associate Editor, CMAJ, I867 Alta Vista Dr., Ottawa ON KIG 3Y6; 6I3 565-547I;

eric.wooltorton@cma.ca 